\title{
STUDI IMPLEMENTASI SISTEM PENYIMPANAN OBAT BERDASARKAN STANDAR PELAYANAN KEFARMASIAN DI APOTEK SEJATI FARMA MAKASSAR
}

\author{
H. Asyhari Asyikin*) \\ ${ }^{*}$ Jurusan Farmasi Poltekkes Kemenkes Makassar
}

\begin{abstract}
ABSTRAK
Telah dilakukan penelitian mengenai Studi Implementasi Sistem Penyimpanan Obat Berdasarkan Standar Pelayanan Kefarmasian di Apotek Sejati Farma Makassar pada bulan Pebruari 2018. Penelitian ini ber tujuan untuk mengetahui seberapa besar implementasi sistem penyimpanan obat berdasarkan standar pelayanan kefarmasian di Apotek Sejati Farma Makassar. Penelitian ini dilakukan dengan cara mengobservasi langsung sistem penyimpanan di Apotek tersebut. Observasi langsung dilakukan dengan sistem check list menggunakan tabel pengamatan, kemudian dihitung persentase implementasi sistem penyimpanan berdasarkan standar pelayanan kefarmasian di apotek tersebut (Permenkes RI Nomor 35 tahun 2014). Hasil penelitian menunjukkan bahwa dari sembilan parameter penilaian sistem penyimpanan berdasarkan standar pelayanan kefarmasian di apotek, 7 parameter telah sesuai dengan persyaratan sistem penyimpanan obat yang baik (persentase penilaian 100\%). Yaitu meliputi obat disimpan sistem First in Firts Out (FIFO), obat disimpan dengan sistem First Expired First Out (FEFO), disimpan sesuai bentuk sediaan, disimpan secara alfabetis, obat narkotika dan psikotropika disimpan terpisah dalam lemari khusus. 2 parameter yang tidak sesuai dengan persyaratan sistem penyimpanan obat yang baik (persentase penilaian 0\%), meliputi penyimpanan sediaan farmasi yang penampilan dan penamaan yang mirip (LASA) masih ditempatkan berdekatan dan petugas tidak memperhatikan tanggal kadaluarsa obat. Berdasarkan hasil penelitian ini, maka dapat disimpulkan bahwa implementasi sistem penyimpanan obat yang baik di Apotek Sejati Farma Makassar adalah sebesar 77,78\% dan berada dalam kategori baik (61-80\%).
\end{abstract}

\section{Kata kunci : Sistem penyimpanan obat, Standar Pelayanan Kefarmasian, Apotek Sejati} Farma Makassar

\section{PENDAHULUAN}

Pelayanan kefarmasian dewasa ini telah terjadi perubahan paradigm dari drug oriented menjadi patient oriented yang bertujuan untuk meningkatkan kualitas hidup pasien. Pelayanan yang bermutu selain mengurangi risiko terjadinya medication error, juga memenuhi kebutuhan dan tuntutan masyarakat sehingga masyarakat akan memberikan persepsi yang baik terhadap apotek terutama kecepatan pelayanan dan ketersediaan obat yang di butuhkan (Handayani, 2009).

Salah satu faktor yang mendukung penjaminan mutu obat adalah bagaimanapenyimpanan obat yang tepat dan sesuaidengan standar yang telah ditetapkan. Kegiatan penyimpanan disini mencakup tiga faktor yaitu pengaturan ruangan, penyusunan obat, serta pengamatan mutu fisik obat (Linarni \&Hasanbasri, 2012).

bagian Penyimpanan obat merupakan bagian yang tak terpisahkan dari keseluruhan kegiatan kefarmasian, baik farmasi rumah sakit maupun farmasi komunitas. Penyimpanan obat adalah suatu kegiatan menyimpan dan memelihara dengan cara menempatkan obat yang diterima pada tempat yang dinilai aman dari pencurian serta dapat menjaga mutu obat. Sistem penyimpanan yang tepat dan baik akan menjadi salah satu faktor penentu mutu obat yang didistribusikan (IAI, 2015).

Sistem penyimpanan obat yang baik di apotek diatur dalam Permenkes RI Nomor 35 tahun 2014 tentang Standar Pelayanan Kefarmasian di Apotek. Dalam peraturan ini disebutkan bahwa sistem penyimpanan dilakukan dengan memperhatikan bentuk sediaan dan kelas terapi obat serta disusun secara alfabetis, pengeluaran obat memakai sistem First Expire First Out (FEFO) dan Firts In Firts Out (FIFO). Hal yang sama disebutkan dalam Dalam Permenkes RI nomor 58 tahun 2014 tentang Standar Pelayanan 
Kefarmasian di Rumah Sakit, dengan menambahkan bahwa penyimpanan sediaan farmasi, alat kesehatan, dan bahan medis habis pakai yang penampilan dan penamaan yang mirip =LASA ( Look Alike Sound Alike) tidak ditempatkan berdekatan dan harus diberi penandaan khusus untuk mencegah terjadinya kesalahan pengambilan Obat.(IAI,2015)

Obat yang didistribusikan di apotek akan sama dengan obat yang didistribusikan di rumah sakit, meskipun tidak semua jenis obat yang ada di rumah sakit juga tersedia di apotek. Oleh karena itu implementasi sistem penyimpanan obat yang baik di apotek sama dengan sistem penyimpanan obat yang baik di rumah sakit.

Apotek Sejati Farma Makassar, merupakan apotek yang cukup besar dan ramai terletak di tengah Kota Makassar yang mendistibusikan obat untuk melayani resep maupun tanpa resep ke masyarakat. Berdasarkan hasil observasi di apotek Sejati Farma Makassar, tersedia lebih dari seratus jenis obat sehingga apotek tersebut mampu melayani seluruh kebutuhan masyarakat (apotek tersebut masuk dalam kategori apotek yang lengkap). Dengan banyaknya jenis obat yang tersedia dan adanya obatobatan yang bentuk/rupanya dan pengucapannya/namanya mirip, dapat menyebabkan kesalahan dalam pemberiian obat kepada pasien.

Berdasarkan penelitian yang dilakukan oleh Bayang, dkk (2014) menunjukkan bahwa kesalahan dalam pemberian obat disebabkan oleh prosedur penyimpanan obat yang kurang tepat khususnya untuk obat LASA (Look Alike Sound Alike) yaitu obat-obatan yang bentuk/rupanya dan pengucapannya/namanya mirip.Selain itu, dalam penelitian Silvia dkk (2011) disebutkan lebih dari satu kesalahan peresepan, total 1.632 kesalahan, ditemukan dalam obat yang perlu kewaspadaan tinggi/high alert, maka dari itu sangat penting bagi tenaga kefarmasian untuk mengelola penyimpanan yang sesuai untuk obat-obat high alert agar meminimalisir kesalahan pada s aat pemberian obat high alert. Berdasarkan penelitian sebelumnya yang pernah terjadi dalam hal pemberian obat yang salah karena faktor penyimpanan obat yang tidak sesuai. Cara yang paling efektif untuk menangani permasalahan kesalahan pemberian obat yaitu dengan cara memperbaiki sistem penyimpanannya.

Penelitian tentang sistem penyimpanan obat berdasarkan standar pelayanan kefarmasian belum pernah dilakukan di Apotek ini sehingga kasus tersebut perlu diambil sebagai bahan penelitian. Oleh karena itu dilakukan penelitian tentang Studi Implementasi Sistem Penyimpanan Obat Berdasarkan Standar Pelayanan Kefarmasian di Apotek Sejati Farma Makassar.

Berdasarkan uraian diatas, maka timbul permasalahan bagaimana implementasi sistem penyimpanan Obat Berdasarkan Standar Pelayanan Kefarmasian di Apotek Sejati Farma Makassar ?

Tujuan penelitian ini adalah untuk mengetahui seberapa besar implementasi sistem penyimpanan Obat Berdasarkan Standar Pelayanan Kefarmasian di Apotek Sejati Farma Makassar.

Sedangkan manfaat dari penelitian ini yang diharapkan memberikan informasi kepada farmasis tentang sistem penyimpanan obat yang baik, sehingga pasien memperoleh obat yang baik dan benar serta aman dan kepada pihak Manajemen Apotek Sejati Farma Makassar tentang sistem penyimpanan obatnya yang berpotensi menyebabkan terjadinya salah ambil obat yang berdampak pada kelangsungan usaha apotek (Medication Error) serta juga dapat dijadikan bahan referensi untuk penelitian berikutnya yang terkait dengan penelitian ini.

\section{METODE DAN BAHAN \\ Jenis Penelitian}

Penelitian ini merupakan penelitian observasional yang bersifat deskriptif, yang bertujuan untuk melihat implementasi sistem penyimpanan obat Berdasarkan Standar Pelayanan Kefarmasian di Apotek Sejati Farma Makassar.

\section{Waktu dan Tempat Penelitian}

Penelitian ini dilakukan pada bulan Pebruari 2018 di Apotek Sejati Farma Makassar

\section{Populasi dan Sampel}

Populasi penelitian ini adalah seluruh obat yang tersedia di Apotek Sejati 
Farma Makassar. Sedangkan sampel penelitian ini adalah seluruh obat yang tersedia di Apotek Sejati Farma Makassar (total populasi).

\section{Prosedur Kerja}

1. Tahap pertama

a. Mengajukan surat izin penelitian ke manajemen Apotek Sejati Farma Makassar. b. Mengobservasi obat-obatan yang tersedia di Apotek Sejati Farma makassar, terkait dengan nama obat dan sistem penyimpanan obat-obat tersebut.

2. Tahap Kedua

Pengumpulan data dilakukan melalui pengisian lembar check list dengan pengamatan dan wawancara bebas terpimpin. Obat-obat yang disimpan tidak sesuai aturan, dicatat.

Tabel 1. Lembar check list sistem penyimpanan stock obat

\begin{tabular}{|c|c|c|c|c|}
\hline No & Aspek yang diobservasi & Ya & tidak & Keterangan \\
\hline 1 & $\begin{array}{l}\text { Petugas menyusun obat dengan memperhatikan metode } \\
\text { FIFO }\end{array}$ & & & \\
\hline 2 & $\begin{array}{l}\text { Petugas menyusun obat dengan memperhatikan metode } \\
\text { FEFO }\end{array}$ & & & \\
\hline 3 & Petugas menyusun obat menurut bentuk sediaan & & & \\
\hline 4 & Petugas menyusun obat secara Alfabetis & & & \\
\hline 5 & $\begin{array}{l}\text { Menggunakan lemari khusus untuk menyimpan } \\
\text { narkotika }\end{array}$ & & & \\
\hline 6 & Menggunakan lemari khusus untuk psikotropika & & & \\
\hline 7 & $\begin{array}{l}\text { Penyimpanan sediaan farmasi yang penampilan dan } \\
\text { penamaan yang mirip (LASA) tidak ditempatkan } \\
\text { berdekatan untuk mencegah terjadinya medication } \\
\text { error }\end{array}$ & & & \\
\hline 8 & $\begin{array}{l}\text { Petugas melakukan pencatatan secara teratur terhadap } \\
\text { obat yang keluar pada kartu stock }\end{array}$ & & & \\
\hline 9 & $\begin{array}{l}\text { Petugas melakukan pemeriksaan tanggal kadaluarsa } \\
\text { obat }\end{array}$ & & & \\
\hline
\end{tabular}

Kolom keterangan diisi sesuai penjelasan petugas terkait dengan aspek yang diobservasi melalui wawancara dengan petugas apotek.

\section{Analisis Data}

Data check list diskoring dan dipersentasekan, kemudian disajikan dalam bentuk tabel.Skor empirik (skor perolehan) dihitung berdasarkan kriteria berikut :

$$
\begin{array}{ll}
\text { Ya } & \text { : skor } 1 \\
\text { Tidak } & \text { : skor } 0
\end{array}
$$

Persentase implementasi dihitung dengan rumus : $\frac{\text { skor empirik }}{\text { skor ideal }}$ x $100 \%$

Skor ideal $=9 \times 1=9$
Selanjutnya datadianalisa secara deskriptif, persentase implementasi sistem penyimpanan obat yang baik terbagi menjadi lima kriteria, yaitu:

1. sangat baik $: 81 \%-100 \%$

2. baik : $61 \%-80 \%$

3. cukup baik $: 41 \%-60 \%$

4. kurang baik : $21 \%-40 \%$

5. sangat kurang baik : $0 \%-20 \%$

\section{HASIL DAN PEMBAHASAN \\ Hasil Penelitian}

Setelah dilakukan penelitian untuk mengetahui seberapa besar implementasi sistem penyimpanan obat yang baik di Apotek Sejati Farma Makassar, diperoleh hasil sebagai berikut : 
Tabel 2. Implementasi sistem penimpanan obat di Apotek Sejati Farma Makassar

\begin{tabular}{clccc}
\hline No & \multicolumn{1}{c}{ Aspek yang diobservasi } & $\begin{array}{c}\text { Skor } \\
\text { Empirik } \\
(\mathrm{n})\end{array}$ & $\begin{array}{c}\text { Skor } \\
\text { Ideal } \\
(\mathrm{N})\end{array}$ & $\begin{array}{c}\text { Persentase } \\
(\%)\end{array}$ \\
\hline 1 & $\begin{array}{l}\text { Menerapkan sistem FIFO pada penyimpanan } \\
\text { obat }\end{array}$ & 1 & 1 & 100 \\
2 & 1 & 1 & 100 \\
& $\begin{array}{l}\text { Menerapkan sistem FEFO pada penyimpanan } \\
\text { obat }\end{array}$ & 1 & 1 & 100 \\
3 & $\begin{array}{l}\text { obat disimpan menurut bentuk sediaan } \\
\text { obat disimpan secara Alfabetis }\end{array}$ & 1 & 1 & 100 \\
5 & $\begin{array}{l}\text { Menggunakan lemari khusus untuk menyimpan } \\
\text { narkotika }\end{array}$ & 1 & 1 & 100 \\
6 & $\begin{array}{l}\text { Menggunakan lemari khusus untuk menyimpan } \\
\text { psikotropika }\end{array}$ & 1 & 1 & 100 \\
7 & $\begin{array}{l}\text { Penyimpanan sediaan farmasi yang penampilan } \\
\text { dan penamaan yang mirip (LASA) tidak } \\
\text { ditempatkan berdekatan untuk mencegah } \\
\text { terjadinya medication error }\end{array}$ & 0 & 1 & 0 \\
8 & $\begin{array}{l}\text { Dilengkapi kartu stok obat } \\
\text { Petugas melakukan pemeriksaan tanggal } \\
\text { kadaluarsa obat }\end{array}$ & 1 & 1 & 100 \\
$\quad$ Total & $\mathbf{7}$ & $\mathbf{9}$ & 0 \\
\hline
\end{tabular}

Sumber : Data Primer 2018

\section{Pembahasan}

Sistem penyimpanan yang tepat dan baik akan menjadi salah satu faktor penentu mutu obat yang didistribusikan. Sistem penyimpanan obat yang baik di apotek diatur dalam Permenkes RI Nomor 35 tahun 2014 tentang Standar Pelayanan Kefarmasian di Apotek. Penelitian ini dilakukan untuk melihat seberapa besar implementasi sistem penyimpanan obat yang baik menurut Permenkes tersebut di Apotek Sejati Farma makassar.

Penelitian ini dilakukan dengan cara mengobservasi langsung sistem penyimpanan di Apotek Sejati Farma makassar dan dengan melakukan wawancara dengan farmasis yang ada di apotek tersebut. Hasil penelitian ini kami bahas dalam uraian berikut ini :

Berdasarkan hasil pengamatan di Apotek Sejati Farma Makassar, diketahui bahwa dari sembilan parameter penilaian sistem penyimpanan obat yang baik, 7 parameter telah sesuai dengan persyaratan sistem penyimpanan obat yang baik (persentase penilaian 100\%). Yaitu meliputi obat disimpan sistem First in Firts Out (FIFO), obat disimpan dengan sistem First Expired First Out (FEFO), disimpan sesuai bentuk sediaan, disimpan secara alfabetis, masing-masing obat memiliki kartu stock.
Apotek ini juga menggunakan lemari khusus untuk menyimpan obat/bahan obat sediaan narkotika dan psikotropika yang dikunci ganda yang terbuat dari kayu. Dua parameter yang tidak sesuai dengan persyaratan sistem penyimpanan obat yang baik (persentase penilaian 0\%), meliputi penyimpanan sediaan farmasi yang penampilan dan penamaan yang mirip (LASA) masih ditempatkan berdekatan dan petugas tidak memperhatikan tanggal kadaluarsa obat.

Berdasarkan hasil observasi langsung tersebut, maka dilakukan
wawancara untuk mendapatkan penjelasan terhadap temuan penelitian yang menunjukkan adanya ketidak sesuaian sistem penyimpanan di Apotek Sejati Farma Makassar dengan sistem penyimpanan obat yang baik. Hasil wawancara dengan salah satu farmasis sebagai informan adalah sebagai berikut:

1. Obat/sediaan farmasi yang penampilan dan penamaan yang mirip (LASA)

Apotek ini menyimpan sediaan farmasi yang memiliki penampilan dan penamaan yang mirip atau biasa disebut LASA (Look Alike Sound Alike) ditempat yang berdekatan. Definisi LASA (Look Alike Sound Alike Drugs) adalah obat-obat yang tampak kelihatan mirip (nama obat, rupa/bentuk obat dan 
dalam pengucapan nama obatnyapun mirip). Karena hal ini dapat menimbulkan medication error dan menyebabkan dampak yang serius terhadap pasien jika terjadi kesalahan dalam penggunaannya dan sebaiknya dibedakan tempat penyimpanannya.

Hasil wawancara dengan dengan informan adalah sebagai berikut :

"Obat-obat yang penampilannya mirip terutama obat generik yang zat aktifnya sama tetapi kekuatannya beda, masih kita simpan berdekatan. Contohnya obat ini (menunjuk obat captopril $25 \mathrm{mg}$ dan $50 \mathrm{mg}$ ), kami tempatkan berdekatan karena sistem penyimpanan di apotek ini sesuai bentuk dan sesuai urutan hurufnya. Sering memang petugas salah mengambil obat dari ruang penyimpanan terutama obat-obat LASA tadi, dengan adanya beberapa tahap dalam penyiapan resep pasien kami yakin tidak akan terjadi kesalahan dalam pemberian obat tersebut. Kalo ada resep masuk, maka harus mengikuti aturan pelayanan yang ada di apotek ini. Jadi kemungkinan adanya medication error sangat kecil, meskipun disimpan dirak yang sama atau berdekatan".

Berdasarkan hasil observasi, prosedur pelayanan resep di Apotek Sejati Farma mengikuti alur berikut :

a. Tahap I : Skrining resep, dilakukan

1. pemeriksaan kelengkapan resep dan keaslian resep untuk obat prekursor, psikotropik dan narkotika

2. pemeriksaan dosis obat

3. konsultasi dengan dokter tentang resep apabila diperlukan

b. Tahap II : penyiapan sediaan farmasi yang dilakukan oleh farmasis bagian gudang/ruang penyimpanan obat sesuai dengan permintaan resep

c. Tahap III : pemeriksaan kembali kesesuaian resep dengan obat oleh farmasis di bagian labeling, kemudian farmasis menyiapkan etiket sesuai dengan permintaan resep untuk diserahkan kepada pasien.
2. Petugas tidak memperhatikan tanggal kadaluarsa obat

Meskipun di apotek ini pada saat pengambilan obat petugas tidak memperhatikan masa kaluarsa obat, tetapi karena obat telah disimpan sesuai dengan sistem FEFO maka tidak ditemukan adanya obat yang kadaluarsa dalam laporan stock opname apotek setiap tahunnya.

"Obat-obat di apotek yang masa kadaluarsanya sudah dekat, kita simpan dibagian depan. Petugas selalu mengambil obat yang ada dibagian depan. Jadi tidak perlu lagi mereka lihat tanggal kadaluarsanya toh, karena di apotek ini banyak sekali pasien sehingga kita harus melayani dengan cepat dan tidak ada waktu untuk melihat lagi kemasannya itu obat"

Hasil persentase (\%) yang diperoleh dari sistem penyimpanan obat yang memenuhi pengaturan/penyusunan stok obat masuk kedalam kategori baik (61\%-80\%) dengan jumlah persentase $77,78 \%$. Hal ini menunjukkan bahwa sistem penyimpanan obat di Apotek Sejati Farma Makassar ini sudah mengikuti standar penyimpanan obat menurut standar pelayanan farmasi di apotek.

Mengingat masih adanya parameter sistem penyimpanan obat yang belum sesuai, terutama sistem penyimpanan obat LASA di Apotek Sejati Farma Makassar. Maka walaupun obat terletak dalam kelompok abjad yang sama harus diselingi dengan minimal dua obat dengan kategori LASA diantara atau ditengahnya. Banyaknya nama obat membuat medication error didasarkan pada penampilan yang mirip atau suara ketika ditulis atau diucapkan atau juga telah diidentifikasi memiliki potensi yang membingungkan. Oleh karena itu sebagai tenaga kefarmasian kita bertanggung jawab penuh untuk mengatasi kesalahan tersebut. Sehingga disarankan kepada pihak aptek untuk lebih memperhatikan sistem penyimpanan obat LASA tersebut.

\section{PENUTUP}

\section{Kesimpulan}

Berdasarkan hasil penelitian ini, maka dapat disimpulkan bahwa implementasi sistem penyimpanan obat yang baik berdasarkan standar pelayanan farmasi 
di apotek Sejati Farma Makassar adalah sebesar $77,78 \%$ dan berada dalam kategori baik $(61-80 \%)$

\section{Saran}

1. Untuk mencegah terjadinya kesalahan pemberian obat, maka sarana pelayanan terutama apotek harus mengimplementasikan sistem penyimpanan obat yang baik berdasarkan standar pelayanan farmasi secara menyeluruh (100\%).

2. Diperlukan penelitian lanjutan terutama tentang sistem penyimpanan obat LASA di sarana pelayanan kesehatan lainnya, sehingga kesalahan pemberian obat kepada pasien dapat dicegah sedini mungkin.

\section{DAFTAR PUSTAKA}

Bayang, dkk, 2014, Faktor Penyebab terjadinya Medication Error di RSUD Anwar Makkatutu Kab. Bantaeng, Tesis, Pascasarjana, UNHAS, Makassar

Depkes RI, 2006, Pedoman Konseling Pelayanan Kefarmasian di SaranaKesehatan, Departemen Kesehatan RI: Jakarta

Handayani, R.S., Raharni, dan Gitawati, R, 2009, Persepsi Konsumen Apotek terhadap Pelayanan Apotek di Tiga Kota di Indonesia, Jurnal Makara Kesehatan,Vol.13,No. 1
Hartini, Y.S. dan Sulasmono 2007. Apotek. Penerbit Universitas Sanata Dharma: Yogyakarta

IAI, 2015, Informasi Spesialite Obat Indonesia, PT. ISFI Penerbitan, Jakarta

Linarni, J.,dan Hasanbasri, M.., 2012, Mutu Pelayanan Farmasi di Puskesmas Kota Padang, Tesis, Working Paper KMPK Universitas Gajah Mada, Yogyakarta.

Menkes RI, 2014, Permenkes RI Nomor 35 tahun 2014 tentang Standar Pelayanan Kefarmasian di Apotek, Jakarta

Menkes RI, 2014, Permenkes RI nomor 58 tahun 2014 tentang Standar Pelayanan Kefarmasian di Rumah Sakit, Jakarta

Setiawan, D., Hasanmihardja, M. \& Mahatir, A., 2010, Pengaruh Pelayanan Kefarmasian terhadap Kepuasan Konsumen Apotek di Kabupaten Tegal,Jurnal Farmasi Indonesia, 5(2), 101-107.

Silvia dkk, 2011, Concomitant Prescribing and Dispensing Errors at a Brazilian Hospital: a descriptive Study, Clinical Science P: 16911697 